\title{
LA SENTENCIA DEL TRIBUNAL DE GARANTIAS CONSTITUCIONALES SOBRE LA CONSTITUCIONALIDAD DE LA LEY DE LA BOLSA DE TRABAJO Y LOS PRINCIPIOS DE IGUALDAD Y LIBERTAD
}

César Landa Arroyo

\section{INTRODUCCION}

La sociedad democrática se ha caracterizado por incorporar como un principio fundamental del Estado de Derecho la libertad. Por ella se produce la revolución de Cronwell en Inglaterra en 1688, la Independencia de los Estados Unidos de Norteamérica en 1776 y la Revolución Francesa de 1789.

En efecto, los procesos revolucionarios democráticos se autolegitimaron en un conjunto de Declaraciones de Derechos, como el Bill of Rights de 1689 en Inglaterra, la Declaración de Derechos de Virginia de 1776 en Estados Unidos y la Declaración de Derechos del Hombre y del Ciudadano de 1789 en Francia, reconociendo a la libertad como un derecho natural anterior y superior al Estado. La libertad, al constituir un derecho fundamental del nuevo Estado, es incorporada y garantizada por la Constitución (1).

De esta manera, la libertad se presenta con una doble característica: primero, en un sentido negativo, como el principio en virtud del cual se remueven las estructuras y formas de organizar el poder, en consecuencia, se legitima la ruptura del ancien régime; $\mathrm{y}$, segundo, en un sentido positivo, como un instrumento que fundamenta la creación del nuevo orden democrático y que, a su vez, señala los fines del mismo (2).

(1) SCHMITT, Carl. Teoría de la Constitución. Madrid, 1982; pp. 164174.

(2) Isaiah Berlin señala desde un punto de vista filosófico e histórico que 
Este nuevo ordenamiento democrático, que se hace consustancial a la noción moderna de Constitución, tiene un decurso histórico que demanda su actualización a las nuevas necesidades y proyectos de orden político y social; el cual se manifiesta en el tránsito teórico y práctico del poder autocrático al poder democrático.

Sin embargo, en la actualidad no basta la consagración de la libertad en abstracto, en circunstancias históricas que están gravemente restringidas sus posibilidades de aplicación. En el mundo concreto y real de hoy la libertad de industria, contratación, comercio, trabajo, entre otros, no tiene sentido absoluto o total, si no existe la libertad para crear industrias, para poder contratar o comerciar y obtener empleo.

Sin las condiciones necesarias para el uso de la libertad, ¿qué sentido alcanza ésta?. Precisamente, ante esta cuestión Harold Laski (3) reconoció en Inglaterra de finales del siglo XIX, que era un imperativo democrático el tránsito de la Freedom to al Freedom for, que significó desarrollar y actualizar los principios de libertad del Estado de Derecho; a fin de que todos los hombres tengan no sólo capacidad de goce de la libertad, sino también capacidad de ejercicio de la misma y, en consecuencia, el Estado no pierda legitimidad y la Constitución no quede reducida a una simple hoja de papel (4).

La libertad para, sin embargo, se encuentra estrechamente vinculada a otro gran principio de la historia constitucional moderna: la igualdad, que ha sido soslayada, cuando no concebida como opues-

"la respuesta a la pregunta de que ¿quién me gobierna? es lógicamente diferente de la pregunta ¿en qué medida interviene en mi el gobierno?. En esta diferencia es en lo que consiste en último término el gran contraste que hay entre los conceptos de libertad negativa y libertad positiva". Libertad y Necesidad en la Historia. Revista de Occidente. Madrid, 1974; p. 144.

(3) Cfr. LASKI, Harold. Introducción a la Política. Buenos Aires, 1981; p. 64.

(4) Cfr. LASSALLE, Ferdinand. ¿Qué es una Constitución?. Barcelona, 1976 ; pp. 70-71. 
ta a la libertad, en el pensamiento de Burke y De Tocqueville. En efecto, "todo paso en dirección a la igualdad fue combatido con el argumento de que menoscaba la libertad" (5). Desde un punto de vista concreto diríamos que la realización de la libertad para, no es sino la realización del principio de la igualdad, por cuanto la libertad constituye un presupuesto de la igualdad y la igualdad una condición de la libertad. Este es el sentido profundo que postula Green, al señalar que: "el ideal de la verdadera libertad consiste en que todos los que forman parte de la sociedad humana tengan por igual el máximo poder para hacer de ellos lo mejor" (6).

Esta fórmula kantiana, según la cual la libertad de uno tiene que coexistir con la libertad de los demás, no es más que reconocer la identidad originaria entre libertad e igualdad del Mundo Antiguo (Grecia y Roma)(7); sin embargo, cabe señalar que la libertad del Mundo Clásico no era un derecho superior e individualizable en los hombres, sino que la libertad se diluia frente al valor supremo que era la comunidad (Polis y Civitas); en tanto que en la concepción moderna la libertad constituye un derecho innato del hombre, anterior a la propia comunidad estatal.

Esta identidad filosófica, por otro lado, va a ser desarrollada por Hegel a través del concepto de libertad histórica, que no es sino poner en movimiento de manera integral y concreta la libertad en todos sus supuestos y consecuencias, ideales y materiales.

(5) KRIELE, Martin. Introducción a la Teoría del Estado. Buenos Aires, $1980 ;$ p. 466.

(6) Citado por Berlin, op.cit., p. 147.

(7) Aristóteles señaló en La Politica, 1317b, que "de la libertad, pues, es propio el mandar unas veces y obedecer otras, porque la justicia popular consiste en la igualdad"; es decir, que los hombres libres sólo pueden someterse a una autoridad cuando cualquiera de ellos, por ser iguales, represente a la comunidad. Por su parte, Cicerón, con mayor contundencia, afirma en La República, Barcelona, 1985, cap. XXXI, que "solamente en aquellas sociedades en que el gobierno existe en el pueblo, se encuentra libertad; la libertad que es el mejor de los bienes, y que si no es igual para todos, no es libertad". 
No obstante, el Estado de Derecho en su fase democrática liberal permitió que existiesen grandes diferencias materiales entre sus miembros, generándose una distorsión del fin del Estado: el bienestar general. Este concepto es el que recoge y actualiza el Estado de Derecho en su forma de democracia social; el mismo que es desarrollado, en su perspectiva jurídica, por el constitucionalismo social occidental, a partir de la Constitución Mexicana de Querétaro en 1917, y la Constitución Alemana de la República del Weimar en 1919 (8).

En el Perú, la Constitución de 1920 va a ser la que inicia el curso del constitucionalismo social -y la segunda en América Latina-, continuado luego por la Constitución de 1933 y consagrado por la Constitución de 1979. Demás está señalar que dicho modelo constitucional ha constituido más un propósito de reconocer aquel fin social del bienestar general de todos los peruanos, que una garantía de la realización concreta del bienestar.

Pero, a partir de la creación del Tribunal de Garantías Constitucionales y su rol de garante de la Constitución, se puede percibir una aproximación jurisprudencial accidentada a los supremos valores democráticos de la libertad y la igualdad.

\section{ANALISIS CONSTITUCIONAL}

Con la expedición de la sentencia del Tribunal de Garantías Constitucionales del 13 de agosto de 1990, en la demanda de inconstitucionalidad interpuesta por el Fiscal de la Nación contra la Ley № 25202, Ley de la Bolsa de Trabajo, declarando la constitucionalidad de la misma por el fondo y la forma, se sienta un precedente jurisprudencial en relación al principio de igualdad, que junto al de la libertad constituyen los valores supremos del Estado peruano.

(8) Cfr. ABENDROTH, Wolgang, FORSTHOFF, Ernest y DOEHRING, Karl. El Estado Social. Madrid, 1986; y FIX-ZAMUDIO, Héctor. La Democracia Social y la Constitución Mexicana. En: Modernas Tendencias del Derecho Constitucional en España y América Latina, Revista de la Universidad del Externado de Colombia, No. 3. Bogotá, 1986. 


\section{Igualdad}

La igualdad ante la ley es un derecho de toda persona, recogida por el artículo $2^{\circ}$, inciso 2 de la Constitución; pero también constituye un principio fundante del Estado de Derecho, que en la actualidad alcanza ribetes de valor constitucional constitutivo de la República democrática y social que proclama el artículo $79^{\circ}$ de la Constitución. Pero la igualdad no sólo constituye un derecho y un valor supremo al igual que la libertad, sino que también es un operador constitucional de la transformación económica y social del país, como lo reconoce el artículo $110^{\circ}$ de la Constitución, al señalar que "el régimen económico de la República se fundamenta en principios de justicia social...".

En consecuencia, la igualdad de las personas presenta estos tres niveles constitucionales - como derecho, valor y operador-, que se analizan en la sentencia del Tribunal de Garantías Constitucionales que nos ocupa, aun cuando ésta se haya limitado a pronunciarse sobre la igualdad ante la ley.

En virtud de la Ley № 25202 de la Bolsa de Trabajo, se faculta a los sindicatos de construcción civil para que coloquen hasta el $25 \%$ de los obreros que demanda un constructor (9). Por su parte, el Fiscal de la Nación señala que dicha ley atenta contra la libertad de asociación sindical, porque se obliga a una afiliación gremial al otorgar al sindicato la facultad de cubrir el $25 \%$ de las plazas de los trabajadores de las obras civiles del país. Más aún, continúa el Fiscal de la Nación, se genera una discriminación a favor de las personas registradas en el sindicato, en perjuicio de las no inscritas, constituyendo un caso de violación del derecho de igualdad ante la ley; asimismo, se rompe el equilibrio contractual necesario entre las partes, colocando en una posición jurídica de ventaja al sindicato frente al empleador, con lo cual también se quiebra el principio de igualdad ante la ley.

$\mathrm{Al}$ respecto, cabe señalar desde el punto de vista histórico, que la igualdad ante la ley responde al hecho que el sistema jurídico pre-

(9) Por Decreto Supremo № 022-90-TR reglamentario de la Ley № 25202, se estableció que para tal efecto, el sindicato inscribirá en un registro a los trabajadores interesados, sean integrantes o no del sindicato. 
democrático se fundaba en un conjunto de derechos o privilegios en función del status de las personas, según nobleza, clase u oficio cuando menos; de ahí que la demanda de la burguesía fue la abolición de los privilegios personales, a través de la igualdad de todos los ciudadanos ante la ley; o dicho en otras palabras, que podrían expedirse leyes especiales sólo cuando lo exigiese la naturaleza de las cosas, pero no por la diferencia de las personas.

De esta manera, la igualdad liberal remeció los privilegios estamentales, sobre todo de la nobleza, pero no modificó las estructuras sociales y económicas desigualitarias; por cuanto la burguesía gozaba del poder económico, en tanto que la nobleza, como clase propietaria, básicamente terrateniente, había dejado de ser progresivamente la detentadora del poder económico en una época marcada por la revolución industrial.

La herencia constitucional peruana contemporánea no responde a este principio de igualdad formal propio del Estado liberal, sino que avanza hacia un concepto de igualdad sustantiva; ello es asi, en virtud al modelo de Estado democrático y social de Derecho, según ha reconocido el Tribunal de Garantías Constitucionales en la sentencia que se comenta. En efecto, como señala Kelsen, "el sentido más profundo del principio democrático radica en que el sujeto no reclama libertad sólo para sí, sino para los demás; el yo quiere que también el tú sea libre, porque ve en él su igual" (10).

El planteamiento filosófico-político que integra armónicamente la libertad y la igualdad en el mundo de las ideas, se ve cuestionado en la realidad cuando entran en conflicto dos intereses sociales como el capital y el trabajo, en una realidad como la peruana, con abismos en el orden económico, social y cultural. Tal es el caso de la Cámara Peruana de la Construcción (CAPECO), que se opone a la Bolsa de Trabajo, pero como quiera que no goza de titularidad constitucional para interponer una acción de inconstitucionalidad (11), la incoa el

(10) KELSEN, Hans. Esencia y Valor de la Democracia. Madrid, 1977; p. 138.

(11) Cfr. Constitución Política del Perú, Art. 299. Están facultados para interponer acción de inconstitucionalidad: El Presidente de la Repúbli- 
Fiscal de la Nación Dr. Manuel Catacora González, quien oficia, entonces, de titular de la acción de inconstitucionalidad contra la Ley № 25202, emanada del Congreso Nacional y defendida por la Federación de Trabajadores de la Construcción Civil.

Pero, como en un Estado de Derecho los conflictos sociales se institucionalizan y procesan como hechos jurídicos, cabe delimitar los casos cuando una norma se convierte en discriminatoria, quebrando el principio de igualdad ante la ley, o cuando una norma es diferenciadora, con lo cual se respeta el principio de la igualdad formal.

La discriminación se produce cuando se otorga una preferencia, se realiza una restricción o exclusión que tenga por óbjeto menoscabar el reconocimiento del goce o ejercicio, en términos de igualdad, de los derechos y libertades fundamentales (12). De ahí que el artículo $2^{\circ}$, inciso 2 , de la Constitución Peruana, haya establecido que la igualdad ante la ley no permite discriminación alguna por razón de sexo, raza, religión, opinión o idioma; claro está que dichas causas no son las únicas formas de discriminación, ni que la Constitución, que se funda en el respeto de la persona humana, haya permitido la discriminación por razones de edad, origen étnico, condición civil, impedimento físico, entre otras.

La omisión constitucional sobre estas formas discriminatorias no constituye un silencio negativo, sino un silencio positivo que permite interpretar en materia de derechos de la persona el artículo $2^{\circ}$, inciso 2 , como una cláusula abierta, orientada a proteger al hombre de cualquier tipo de discriminación legal que afecte a la dignidad humana y no solamente a las prescritas en el texto.

Por su parte, el Convenio № 111 - Convenio relativo a la Discriminación en Materia de Empleo y Ocupación, aprobado y ratificado en el Perú-, define y establece el alcance de la prohibición

ca; la Corte Suprema de Justicia; el Fiscal de la Nación; sesenta Diputados; veinte Senadores; y cincuenta mil ciudadanos.

(12) Cfr. O'DONNELL, Daniel. Protección Internacional de los Derechos Humanos. Lima, 1988; p. 373. 
de las discriminaciones, a los motivos de raza, color, sexo, religión, opinión política, ascendencia nacional u origen local; sin embargo, por otro lado, el convenio reconoce que la diferenciación no contraría a la igualdad ante la ley, cuando a determinados grupos de personas basados en razones de sexo, edad, invalidez, carga de familia o nivel social o cultural, se les reconoce una protección o asistencia laboral especial.

En efecto, no todo trato diferente entre las personas, amparado en un acto o ley gubernamental, configura un supuesto de discriminación: por ejemplo, el cobro de impuestos directos, como el impuesto a la renta, diferencia la contribución de las personas al Estado según sus ingresos, mas no las discrimina en función de sus ingresos, "siempre que esa distinción parta de supuestos de hechos sustancialmente diferentes y que expresan, de modo proporcionado, una fundamentada conexión entre esas diferencias y los objetivos de la norma; los cuales no pueden apartarse de la justicia y de la razón, vale decir, no pueden proseguir fines arbitrarios, caprichosos, despóticos o que de alguna manera repugnan a la esencial unidad y dignidad de la naturaleza humana" (13).

Los requisitos de inscripción de los trabajadores de construcción civil en el Registro Especial del Sindicato, a fin de cubrir el 25\% de la mano de obra que demanda una empresa constructora para realizar una obra, según establece la ley y el reglamento de la Bolsa de Trabajo, no excluye que el obrero, sindicalizado o no, que además no desee registrarse, pueda ser contratado dentro del $75 \%$ de libre disponibilidad del empleador. Luego, el trabajador tiene la facultad discrecional de alcanzar una plaza por una vía u otra, pero la diferenciación de los canales de ingreso parte de un hecho real: los trabajadores de construcción civil sindicalizados son discriminados por los contratistas, en tanto plantean reclamos laborales y movilizan las huelgas; pero, por otro lado, el empleador evita contratar a los obreros mayores de cuarenta años, debido a que sobre esa edad el obrero de construcción civil ha desgastado rápidamente su capacidad de rendimiento productivo, debido a la sobre-exigencia física de dicho trabajo; de ahí también que sea un empleo estrictamente masculino.

(13) Ibid., p. 374. 
Entonces, no contratar a los obreros por sus ideas sindicales o edad avanzada, constituye un abuso del derecho, discriminatorio por cuanto se causa daño a un interés no protegido por una específica prerogativa jurídica. En tal entendido, la libertad de contratación discriminatoria, cualquiera sea la causa, constituye un abuso del derecho, "no porque se actúe al margen del ordenamiento jurídico sino dentro de los límites de él, pero contrariando sus fines, violando su espíritu, lo cual convierte en contrario al derecho" (14).

Esta figura ofensiva a la dignidad humana, constituye una discriminación de facto que repulsa al principio de la igualdad de las personas; de modo que la discriminación de facto viene a ser superada por la Ley № 25202, por una diferenciación proporcional de jure, otorgando un $25 \%$ de cuota de empleo sindical, que nivele en todo caso la discriminación empresarial. Dicho en palabras de los magistrados del Tribunal de Garantías Constitucionales, en la sentencia del 13 de agosto de 1990, "la Ley veinticinco mil doscientos dos, lejos de atentar contra la igualdad de trato, lo que en realidad hace es restablecer la igualdad de trato perdida por la discriminación patronal introducida por el empleador" (15).

Más aún, no sería inconstitucional si la ley hubiese tenido por objeto asegurar a estos grupos marginados o discriminados por edad, ideas o afiliación, un ejercicio igualitario de sus derechos y libertades fundamentales conculcadas en la práctica (16). Esta suerte de dife-

(14) TORRES VASQUEZ, Anibal. El Abuso del Derecho. Revista de Derecho y Ciencias Políticas, vol. 45, años 1981-1985. Lima 1990; p. 114.

(15) Esta línea jurisprudencial, a nivel comparado, sigue la iniciada por el Tribunal Constitucional Español en la sentencia del 10 de julio de 1981 , en la que se señala que "el principio de igualdad ha de entenderse en función de las circunstancias que concurren en cada supuesto concreto en relación con el que se invoca (...). Sólo podría deducirse la quiebra del principio de igualdad, cuando dándose los requisitos previos de una igualdad de situaciones entre los sujetos afectados por la norma, se produce un tratamiento diferenciado de los mismos en razón a una conducta arbitraria o no justificada de los poderes públicos". Al respecto, consultar a ALVAREZ CONDE, Enrique, El Régimen Político Español. Madrid, 1987; p. 115.

(16) Así, por ejemplo, lo ha entendido la legislación internacional, a través 
renciación o discriminación positiva, se funda en un principio de equidad o justicia distributiva, propia del Estado social y democrático de Derecho, que no constituye un mandato de orden y programático, sino un mandato de orden jurídico aplicable hic et nunc.

En tal sentido, la búsqueda de realización de la igualdad, a través del principio de diferenciación o discriminación positiva, debe vincularse estrechamente con el respeto de los derechos y libertades de las personas.

\section{Libertad}

El Fiscal de la Nación afirma que la Ley de la Bolsa de Trabajo atenta contra la libertad de asociación sindical y la libertad de contratación, consagradas en la Constitución (17).

\subsection{Libertad de sindicación}

En relación a la libertad de sindicación, se señala que la facultad otorgada al sindicato en la ley, plantea una exigencia de

de la Convención de las Naciones Unidas sobre la Eliminación de Todas las Formas de Discriminación Contra la Mujer de 1979. Desde el Derecho Comparado, la legislación norteamericana federal y estatal también confirma la protección de las minorías contra la discriminación; sobre el particular, consultar a Charles Grimm, Employment Discrimination, pág. 1, para quien "si bien es imposible eliminar todas las formas de discriminación en el empleo, el Congreso de los Estados Unidos ha visto apropiado crear la protección del empleo para ciertos grupos de gente que son usualmente discriminados por el simple motivo de poseer una característica grupal". Asimismo, consultar a Geoffrey Stone, Luis Seidman, Cass Sunstein, Mark Tushnet, Constitlution Law. Boston, 1986; p. 240.

(17) Al respecto, se puede revisar los artículos de Alfredo Villavicencio y David Lobatón, La Bolsa de Trabajo, Razón de Ser y Fundamento Constitucional; y a Felipe Cantuarias, La Inconstitucionalidad de la Bolsa de Trabajo; ambos en la revista de estudiantes de derecho de la Universidad Católica, Derecho y Sociedad, año 2, № 3. Lima, 1990. 
afiliación sindical para poder ocupar una de las plazas del $25 \%$ de una obra asignada al gremio laboral. Si bien la Ley № 25022 sólo establece que las plazas "serán cubiertas por los Sindicatos de Trabajadores de Construcción Civil de la República...", tal precepto dio lugar a que la demanda se plantease en los términos de que se exigía la afiliación sindical. Sin embargo, el DS № 022-90-TR, reglamentario de la Ley, dispuso en su artículo $7^{\circ}$ que "los trabajadores de construcción civil deberán registrarse en los sindicatos que representen a dicha actividad, a efecto de gozar del beneficio a que se contrae la Ley № 25022, sin requerirse para ello su previa afiliación".

Sin embargo, el problema central no constituye el demandado realmente, sino que los magistrados del Tribunal encargados de declarar la constitucionalidad o inconstitucionalidad de la Ley de la Bolsa de Trabajo, la compulsan con una norma reglamentaria inferior a la Constitución y a la ley, y no con la norma constitucional, según dispone el artículo $298^{\circ}$ de la Constitución. ¿Con lo cual acaso se estaría acarreando un vicio in iudicando por la errónea aplicación de la ley?

Sobre el particular, el artículo $21^{\circ}$ de la Ley № 23385, Ley Orgánica del Tribunal de Garantías Constitucionales, permite que el Tribunal, para resolver sobre la constitucionalidad o inconstitucionalidad de una ley, deba considerar además de los preceptos constitucionales, las leyes que determinen la competencia de los órganos del Estado. Esto significa que la norma constitucional no bastaría por si sola sino que ocasionalmente deben añadirse las leyes que complementan la norma constitucional abierta o incompleta, formando así el llamado bloque de constitucionalidad. De tal manera que el núcleo esencial de la Constitución no estaría contenido exclusivamente en su texto, sino que alcanzaría a normas formalmente inferiores a la propia Constitución (18).

(18) El bloque de constitucionalidad comprende a la Constitución material o sustancial y a los elementos constitucionales y legislativos básicos, que clarifican la fórmula de la libertad constitucional; esta tesis incorporada en el artículo $21^{\circ}$ de la Ley Orgánica del Tribunal de Garantías Constitucionales, ha sido tomada del artículo 28.2 de la Ley Orgánica del Tribunal Constitucional Español; lo cual le ha permitido a este tribunal crear una abundante jurisprudencia constitucional. Al res- 
En efecto, la noción de Constitución formal queda completada con la noción de Constitución material o sustancial, según la cual "puesto que el derecho constitucional como derecho del hecho político, además de las libertades fundamentales, debe preocuparse de la vigencia real $\mathrm{y}$, por ende, de la efectividad de la prescripción, puede conectarse también con actos formalmente no calificados de constitucionales, como, por ejemplo, leyes y sentencias de los Tribunales 0 con hechos normativos" (19).

En tal sentido, el Tribunal de Garantias Constitucionales decidió en mayoría que la Ley № 25022 no violaba la libertad sindical y por tanto, era constitucional, no tanto en relación al propio articulado de la Constitución, sino en función al reglamento de la Ley de la Bolsa de Trabajo, por cuanto el reglamento de la Ley de la Bolsa de Trabajo define terminantemente que la inscripción en el sindicato no es un requisito sine qua non para alcanzar el $25 \%$ de las plazas que el gremio coloca en la obra de construcción. La ley, por sí sola, no hubiese permitido definir con claridad meridiana la demanda del Fiscal de la Nación, en el sentido que la Ley $\mathrm{N}^{\circ} 25022$ exigía la afiliación sindical, violándose la libertad sindical.

Esto significa que el reglamento estaría siendo incorporado al bloque de constitucionalidad; con lo cual se podría llegar al absurdo constitucional siguiente: por un lado, flexibilizar tanto la noción de bloque constitucional que alcance hasta las normas reglamentarias de naturaleza derivada, es decir complementarias directamente de la ley o indirectamente de la Constitución; y por otro lado, al ser el bloque de constitucionalidad un sistema rígido inviolable, su modificación en el caso de las normas de inferior jerarquía que la Constitución, debería legalmente realizarse mediante una ley ordinaria del Congreso o un acto administrativo del Gobierno; sin embargo, se

pecto, consultar a Pablo Lucas Verdú, Curso de Derecho Político, volumen IV. Madrid, 1984, pp. 391-393; asimismo se puede revisar a Javier Perez Royo, Reflexiones sobre la Contribución de la Jurisprudencia Constitucional a la Construcción del Estado Moderno, Revista de Estudios Políticos, № 49. Madrid, 1986; pp. 23-35.

(19) DE VERGOTTINI, Giussepe. Derecho Constitucional Comparado. Madrid, 1983; p. 139. 
estaría afectando la legitimidad de la obra del poder constitucionalconstituyente que ha erigido el llamado bloque de constitucionalidad.

La alternativa del Tribunal de Garantías Constitucionales, entonces, para no apelar al reglamento y evitar las disritmias constitucionales señaladas, hubiese sido que, al no encontrar elementos de juicio dirimentes en la Ley № 25022 para afirmar o negar la inconstitucionalidad de la norma por violación de la libertad sindical, se pronunciase en función del indirizzo político y la realidad social, estableciendo el derrotero constitucional de carácter social y, en este sentido, los lineamientos del contenido legislativo y reglamentario, desarrollados o a desarrollar por el Congreso y el Poder Ejecutivo.

Sin embargo, el Tribunal resolvió directamente sobre la causa y para el efecto apeló al reglamento de la Ley, en un proceso excesivo de ingeniería constitucional, según la cual la actuación constitucional no se reduce a la defensa del ordenamiento del sistema jurídico constitucional, en base a normas exclusivamente, sino también en función a criterios constitucionales de carácter político, económico y social.

En efecto, la prolífica doctrina constitucional italiana (Cheli, Compagna, Lavagna, Scalfaro, Di Ciolo y Frosini), autora de este instituto, señala que "la ingeniería constitucional es una compensación socio-política a las tendencias expansionistas del método técnico-jurídico concebidas como simple jurisprudencia de conceptos" (20). Lo cual tiene mayor vigencia en el Perú, en una época de grave crisis constitucional (social, política y económica), donde la defensa de la Constitución no puede reducirse absolutamente a estrechas consideraciones normativas o institucionales, manejadas desde métodos y técnicas jurídicas clásicas.

En tal sentido, el criterio jurisprudencial del Tribunal de Garantías Constitucionales constituye expresión cabal de entender a la Constitución y al propio Tribunal como operadores de la transformación institucional que reclama el constitucionalismo social, al cual se encuentra inscrito el Derecho Constitucional peruano. De manera

(20) LUCAS VERDU, Pablo. Op.cit.; p. 125. 
tal que la actuación ética y socialmente constitucional de los magistrados no es contraria a los fines de la Constitución; sin embargo, la tácita interpretación constitucional conforme al bloque de constitucionalidad realizada, peca de falta de doctrina y técnica constitucional, que perfeccione jurídicamente y no sólo resuelva eficazmente la organización y funcionamiento del conjunto de derechos y libertades, que consagra el ordenamiento democrático y social que rige a la Constitución de 1979.

\subsection{Libertad de contratar}

En cuanto a la libertad de contratar, se argumenta que la Ley de la Bolsa de Trabajo vulnera la autonomía de la voluntad, que es esencial para ejercer la libertad de contratación; por cuanto la norma obliga al empleador a contratar un $25 \%$ de los obreros registrados en el sindicato de construcción civil.

La contratación es un acto de orden civil, que está reconocido por el ordenamiento jurídico constitucional, en tanto existe y es gestora de las relaciones personales y patrimoniales de los ciudadanos. Sin embargo, su vigencia está a condición de que sus fines sean lícitos y que se salvaguarde los principios de justicia social y se evite el abuso del derecho, según dispone el artículo $2^{\circ}$ inciso 12 de la Constitución. En tal sentido, queda sentado que la libertad de contratación es un derecho fundamental relativo, no absoluto (21).

La autonomía de la voluntad empresarial, en consecuencia, puede estar limitada en virtud de una obligación que le confiera la ley. Es decir que por obra del ius imperium del Estado se pueden desarrollar obligaciones contractuales, orientadas a proteger los mandatos que delimitan la libertad de contratación de la Constitución. En estos casos, "la fuente de la obligación sólo puede ser un acto

(21) Cfr. SCHMITT, Carl. Op.cit., pp. 169-175; donde el autor señala que los auténticos derechos fundamentales son los derechos absolutos; es decir, no se garantizan con arreglo a ley, como la vida, la libertad de religión, la libertad personal y la libertad de conciencia. En tanto que los derechos fundamentales relativos se arreglan a la ley; en efecto, en el intercambio económico rige la libertad de contratación de acuerdo a ley, en sus formas, garantías y límites. 
de un órgano estatal que ostenta un poder suficiente y a quien el ejercicio de dicho poder le autoriza para constituir entre particulares relaciones jurídicas de derecho privado" (22).

De modo que, siguiendo las premisas democráticas del ordenamiento político, social y económico constitucional (indirizzo politico), la Ley $\mathrm{N}^{\circ} 25022$ busca restablecer el equilibrio contractual de las partes, limitando la posición material de ventaja del contratista y garantizando jurídicamente, en un porcentaje limitado, el ejercicio de la libertad de contratación para el que demanda empleo y es discriminado y no sólo para quien ofrece empleo.

Más aún, se puede ver el problema a partir de la integración de derechos, que no es sino abordar la temática de la interpretación de los dispositivos constitucionales, cuando se encuentran dos derechos o libertades constitucionales en contradicción, como la libertad de contratación y el derecho al trabajo.

La función de la interpretación constitucional en estos casos no se reduce a encontrar el mejor derecho garantizado por la Constitución, sino que, al haberse integrado dos libertades o derechos en la norma suprema del Estado, se entiende que existe una protección de ambos bienes jurídicos. De ahí que uno no pueda ser entendido como excluyente del otro, sino que se trata de "establecer los límites de ambos bienes a fin de que ambos alcancen una efectividad óptima. La fijación de límites debe responder en cada caso concreto al principio de proporcionalidad" (23). Para lo cual se debe establecer una relación proporcional entre el derecho al trabajo y la libertad de contratación, que responda a los principios de unidad de la Constitución.

(22). DIEZ-PICAZO, Luis. Fundamentos del Derecho Civil Patrimonial. Vol. I. Madrid, 1983; p. 406. Una tesis opuesta a la reseñada la expresa DE LA PUENTE, Manuel, Estudios del Contrato Privado, Tomo I. Lima, 1979; p. 63, para quien "es antitético de la libertad de contratar la obligación de contratar con determinadas personas... ( $\sin$ embargo)... las legislaciones están llenas de casos en que existe esta limitación a la libertad de contratar.

(23) HESSE, Konrad. Escritos de Derecho Constitucional. Madrid, 1983; p. 48. 
De acuerdo con lo señalado, ¿qué razón más proporcional y equitativa que la Ley de la Bolsa de Trabajo reserve un $75 \%$ de la mano de obra a la libre disponibilidad de contratación del empleador, y un $25 \%$ de asignación de la mano de obra por el Sindicato, a fin de garantizar la igualdad de oportunidad en el empleo y así evitar la discriminación laboral?

Finalmente, cabe recordar que el ordenamiento constitucional se inspira en una ideología, una organización y una estructura socio-económica, que apuntan a un objetivo, según el cual, "para que pueda originarse la noción de una forma social democrática, la idea de la igualdad ha de agregarse a la de la libertad, limitándola" (24). Este es el postulado que ha concretado el Tribunal de Garantías Constitucionales, al reconocer la constitucionalidad de la Ley $\mathrm{N}$ 25022 , confirmando así su rol de guardián de la Constitución.

Lima, 1990

(24) KELSEN, Hans. Op.cit., p. 138. 